\title{
NOS3 894G > T Gene Polymorphism: A Potential Risk Factor of Stroke in Bahraini Patients
}

\author{
Manal A. Fadl'1, Adel A. AlJishi², Safa Taha ${ }^{3}$, Moiz Bakhiet ${ }^{3}$ \\ ${ }^{1}$ Faculty of Science and Technology, Al Neelain University, Khartoum, Sudan \\ ${ }^{2}$ Salmanyia Medical Complex, Manama, Bahrain \\ ${ }^{3}$ Department of Molecular Medicine, CMMS, Princess Al-Jawhara Center, Arabian Gulf University, Manama, Bahrain \\ Email: manalfadl1@hotmail.com
}

How to cite this paper: Fadl, M.A., AlJishi, A.A., Taha, S. and Bakhiet, M. (2018) NOS3 894G > T Gene Polymorphism: A Potential Risk Factor of Stroke in Bahraini Patients. World Journal of Neuroscience, $\mathbf{8}$, 98-107.

https://doi.org/10.4236/wjns.2018.81009

Received: January 3, 2018

Accepted: February 10, 2018

Published: February 13, 2018

Copyright $\odot 2018$ by authors and Scientific Research Publishing Inc. This work is licensed under the Creative Commons Attribution International License (CC BY 4.0).

http://creativecommons.org/licenses/by/4.0/

\begin{abstract}
The endothelial nitric oxide synthase (eNOS) encoded by the NOS3 gene is responsible for the synthesis of a vasoactive endothelium-derived nitric oxide (NO). The genetic polymorphism of this gene explains, in part, why some people are prone to develop stroke than others. In this study we conducted a case control study in Bahrainis to investigate "for the first time" the relationship between NOS3 894G > T (rs1799983) and 786T > C (rs2070744) polymorphisms with the stroke predisposition in Bahraini population. Detection of NOS3 polymorphism was performed by PCR RFLP genotyping method. The level of NO among cases and controls was measured using ELISA. A total of 93 unrelated stroke patients and 86 controls were included in the study. The three types of stroke; Ischemic, hemorrhagic and transient ischemic attack were reported (91.4\%, 7.5\% and $1.1 \%$ respectively). No significant gender difference was observed $(P=0.74)$. Having previous stroke was a highly significant risk factor of the disease $(P=0.001, \mathrm{OR}=1.4)$, where as a family history of stroke was not $(\mathrm{OR}=0.11)$. The analysis provides evidence that the mutant $894 \mathrm{GT}+\mathrm{TT}$ genotypes of NOS3 894G > T polymorphism were positively associated with stroke predisposition and it increased the risk of stroke nearly two folds $(P=0.037, \mathrm{OR}=1.936)$. Although we found an association between the mutant genotype786 TC + CC of the NOS3 786T > C polymorphism with the susceptibility to stroke $(P=0.023)$ suggesting that the mutant $\mathrm{C}$ allele might have a protective effect against stroke in this population, the strength of this association was rather low $(\mathrm{OR}=0.484)$. The level of NO in stroke patients was significantly low compared to healthy controls $(P<0.005)$. Diabetes, hypertension, heart diseases were reported in stroke patients $(67 \%$, $71.4 \%$ and $52.1 \%$ respectively). More over $50 \%$ of the cases with previous stroke are both diabetic and hypertensive. This indicates that these diseases could be considered as a significant factor in the development of stroke in this
\end{abstract}


population. We concluded that the NOS3-894 G $>$ T polymorphism is a potential risk factor of stroke in Bahraini population, whereas as the NOS3 786 $\mathrm{T}>\mathrm{C}$ polymorphism might have a possible protective role against the disease in this population.

\section{Keywords}

Gene Polymorphisms, Nitric Oxide Synthase, Stroke Risk Factors

\section{Introduction}

A stroke results when the blood supply to the brain is suddenly cut off or interrupted. This can occur when a blood vessel in the brain or neck is blocked or bursts, leading to brain cells' death. Stroke is now a fourth leading cause of death in the developed world [1] and it is a major cause of adult disability. The disease receives an increasing global importance due to its high incidence and mortality which occur as a consequence of adverse lifestyle changes, that increase peoples' predisposition to hypertension, diabetes, heart disease. All are risk factors of stroke [1] [2] [3] [4].

Over a third of stroke deaths occur in developing countries [3]. Arab countries constitute populations with a lifestyle and diet that may influence stroke risk. The incidence of stroke in Bahrainis is rising over the last 16 years $(110 / 100,000)$ [5] compared to the incidence of 57/100,000 reported in 1995 [6].

Stroke is a multifactorial disease, results from a combination of several risk factors, both environmental and genetic factors [7] [8] [9] [10] [11]. Nitric oxide synthase 3 gene (NOS3) of the endothelial cell "located on chromosome 7 (7q36) has received a considerable attention as Nitic oxide (NO), a powerful short-lived vasoactive substance, is constitutively produced from L-arginine by the enzyme eNOS [12]. NO plays a crucial role in the relaxation of vascular smooth muscle [12]. It inhibits platelet and leukocyte adhesion to vascular endothelium [13] [14] [15]. In addition the augmentation of NO production increases cerebral blood flow, which can lead to neuroprotection during brain ischaemia [16].

Case control epidemiological studies or meta analysis on NOS3 polymorphisms although they showed conflicting results; however, some of the studies demonstrate the NOS3 as a significant factor in the development of stroke [17] [18] [19] [20].

As the stroke incidence is increasing in Bahrainis; the knowledge of the conventional risk factors perse is not sufficient to absolutely predicting the development of the stroke process, therefore it is important to understand the genetic contribution to disease predisposition, which might help to apply successful preventive strategies and targeted treatment. Given the importance of the NOS3 gene; this study aimed to investigate "for the first time" the involvement of the NOS3 894G > T and 786T > C polymorphisms in stroke predisposition within Bahraini population. 


\section{Materials and Methods}

\subsection{Demography}

The Bahraini population consists of an Arabian Peninsula population. The Bahrainis represent $61.9 \%$ of the population, whereas $38.1 \%$ were non-Bahrainis [21]. 56\% of the population are within the $15-64$ age groups and those above 65 age group were $3.4 \%$. Consanguineous marriage is common among families which explains the homogeneity observed among the Bahrainis [22].

\subsection{Sample Collection and DNA Extraction}

Blood was collected in EDTA tube from 93 of proven stroke patients who were admitted to Salmaniya Medical Complex (SMC) and 86 unrelated controls during the period from in January 2015 till June 2015. Brain CT scan was performed in all patients within 24 hours of onset of stroke. Informed consent was obtained from patients and controls. The study was approved by the Ethical Committee of the Arabian Gulf University (AGU) and SMC, Ministry of Health, Bahrain.

Genomic DNA was extracted from EDTA buffy coat by the MAGNA PURE and the quality of DNA was checked on Nanodrop Spectrophotometer.

\subsection{Genotyping of the NOS3 Polymorphisms}

In this study we conducted a (PCR-RFLP) analysis of NOS3 identifies G to T substitution at 894 position of exon7 which changes Glu to Asp amino acid at codon 298 and NOS3 786T > C a promoter polymorphisms. PCR amplification was performed in a $12.5 \mu \mathrm{L}$ reaction mixture containing $6.5 \mu \mathrm{L}$ of Promega mixture, $1 \mu \mathrm{L}$ of $10 \mathrm{pmol} / \mu \mathrm{L}$ of each primer, $3-4$ of $\mathrm{ddH}_{2} \mathrm{O}$ and $1-2 \mu \mathrm{L}$ of $50 \mathrm{ng} / \mu \mathrm{L}$ of template DNA. A negative control containing distilled water instead of genomic DNA was prepared. The reaction mixture was mixed and spun. PCR which was carried in an automated thermocycler (BioRad PTC100, USA) with primer pairs: F 5'-GTC CCT GAG GAG GGC ATG AG-3' and R 5'-TCC AGC AGC ATG TTG GAC AC-3' which amplify the 371 bp sequence containing the NOS3 894G > T polymorphism and F5'-GCA GGT CAG CAG AGA GAC TA-3' and R 5'-GAC ACA GAA CTA CAA ACC CC-3' to amplify sequence containing the NOS3 786T > C polymorphism. The PCR program was as follows: $95^{\circ} \mathrm{C}$ for 5 min for initial denaturing, 30 cycles of denaturing at $95^{\circ} \mathrm{C}$ for $30 \mathrm{~s}$, annealing at $64^{\circ} \mathrm{C}$ for $1 \mathrm{~min}$ for the NOS3 $894 \mathrm{G}>\mathrm{T}$ polymorphism and at $61^{\circ} \mathrm{C}$ for $1 \mathrm{~min}$. for NOS3 $786 \mathrm{~T}>\mathrm{C}$, followed by extension at $72^{\circ} \mathrm{C}$ for $30 \mathrm{~s}$. Final extension at $72^{\circ} \mathrm{C}$ for $10 \mathrm{~min}$ to ensure complete amplification of the sequence.

The amplicon of the NOS3 894G > T and NOS3 786T > C polymorphisms were digested with an appropriate restriction enzyme; BanII $\left(\mathrm{NEB}^{\circledR}\right.$, England) and MSP1 (Fermentas, thermos scientific) respectively as per manufacturer's instruction. The digested product was separated on 3\% agarose gel stained with Gel Star and documented on UVTEC CAMBRIDGE, TLC imaging system.

For the NOS3 $894 \mathrm{G}>\mathrm{T}$ the Wild type GG allele $=371 \mathrm{bp}$ and the mutant homozygous generate the restriction position giving mutant allele TT $=233 \mathrm{bp}$ 
and $138 \mathrm{bp}$. The heterozygous indicated by the presence of three fragments, 371 bp, $233 \mathrm{bp}$ and $138 \mathrm{bp}$.

The wild TT of the NOS3 786T > C polymorphism was identified by a band size of $178 \mathrm{bp}$ while the CC mutant allele indicated by CC $=137 \mathrm{bp}$ and $41 \mathrm{bp}$ and the heterozygous by three bands of $178 \mathrm{bp}, 137$ and $41 \mathrm{bp}$.

\subsection{Determination of Plasma Nitrite/Nitrate}

To evaluate $\mathrm{NO}$ production; the plasma levels of nitrite $\left(\mathrm{NO}_{2}^{-}\right)$and nitrate $\left(\mathrm{NO}_{3}^{-}\right)$were measured. 88 Blood samples from both cases and controls were centrifuged, Plasma was separated, then diluted 2-fold in which $100 \mu \mathrm{L}$ of the sample added to $100 \mu \mathrm{L}$ of Reaction Diluent (1X). The $\mathrm{NO}_{\mathrm{x}}^{-}$concentration of the resulting solution was determined by ELISA using a kit (R\&D Systems, Cat \# KGE001, USA) according to manufacturer instructions.

Endogenous nitrite concentration was measured with use of the Griess reaction by adding $100 \mu \mathrm{L}$ of Griess reagent (1\% sulfanilamide and $0.1 \%$ naphthylethylenediamide in $5 \%$ phosphoric acid) to $50 \mu \mathrm{L}$ of plasma and mixed in $96-$ well plates and shaken gently for 20 minutes at room temperature. The addition of the Griess reagent results in a colorimetric product measured at $540 \mathrm{~nm}$ and with correction wavelength at $690 \mathrm{~nm}$. The nitrate is obtained by the incubation with nitrate reductase and NADPH at room temperature for 1 hour that convert the nitrates into nitrites, then the nitrate concentration is obtained by subtracting the endogenous nitrite from the total nitrite value.

\subsection{Statistical Analysis}

SPSS version 21 statistical package was used to count the genotype, chi square, $P$ value, odds ratio (OR) and 95\% confidence interval (CI).

Statistical significance was determined at $P<0.05$.

ORs with $95 \%$ CI was used to assess the strength of the association of the NOS3 gene $894 \mathrm{G}>\mathrm{T}$ and $786 \mathrm{~T}>\mathrm{C}$ polymorphisms of with risk of stroke predisposition.

\section{Result}

A case-control association study recruited 93 unrelated Bahraini stroke patients and 86 healthy control Bahrainis, revealed the presence of the three types of stroke; ischemic $91.4 \%$, hemorrhagic $7.5 \%$ and transient ischemic attack $1.1 \%$.

$55.9 \%$ of the stroke patients were males, $44.1 \%$ were females with no significant gender difference ( $P=0.74$ ) (Table 1$) .57 .8 \%$ of the male stroke patients are within age group $\geq 40$ - 65 compared to the $39.1 \%$ females in the same age group.

$28.9 \%$ of the cases have previous stroke $(P=0.001$, Odds $=1.4$, CI $1.2-1.6)$ indicating the significance of the previous attack as risk factor of the disease, however, a family history of stroke was not found to increase the risk of stroke $(\mathrm{OR}=0.11)($ Table 1$)$. 
Table 1. Comparison of risk factors between stroke patients (cases) and controls.

\begin{tabular}{|c|c|c|c|}
\hline & $\begin{array}{c}\text { Patients } \\
(\mathrm{N}=93) \\
(\%)\end{array}$ & $\begin{array}{c}\text { Controls } \\
(\mathrm{N}=86) \\
(\%)\end{array}$ & $P, \mathrm{OR}, \mathrm{CI} 95 \%$ \\
\hline$\%$ Males & $55.9 \%$ & $53.2 \%$ & $P=0.74$ \\
\hline$\%$ Females & $44.1 \%$ & $46.8 \%$ & \\
\hline$\%$ Previous stroke & $28.9 \%$ & $0.0 \%$ & $\begin{array}{c}P=0.001 \\
\mathrm{OR}=1.4 \\
\mathrm{CI}=1.2-1.6\end{array}$ \\
\hline$\%$ of stroke cases are at age $\leq 40-65$ & $46 / 93(49.5 \%)$ & & \\
\hline$\%$ of stroke of male at age $\geq 40-65$ & $57.8 \%$ & & \\
\hline$\%$ of stroke of female at age $\geq 40-65$ & $39.1 \%$ & & \\
\hline Family history of stroke & 9/93 (9.7\%) & $0.0 \%$ & $\mathrm{OR}=0.11$ \\
\hline NOS3-894G > T & GG 27/92 (29.3\%) & $37 / 83(44.6 \%)$ & \\
\hline Wild type & GT 59/92 (64.1\%) & $43 / 83(51.8 \%)$ & \\
\hline Mutant types & TT 6/92 (6.5\%) & $3 / 83(3.6 \%)$ & $\begin{array}{c}P=0.037 \\
\mathrm{OR}=1.936 \\
\mathrm{CI}=1.04-3.6\end{array}$ \\
\hline$N O S 3-786 \mathrm{~T}>\mathrm{C}$ & $\begin{array}{c}\mathrm{TT}=67 / 92 \\
(72.8 \%)\end{array}$ & $48 / 85(56.5 \%)$ & \\
\hline Wild type & $\begin{array}{c}\mathrm{TC}=22 / 92 \\
(23.9 \%)\end{array}$ & $30 / 85(35.3 \%)$ & \\
\hline Mutant types & $\begin{array}{c}\mathrm{CC}=3 / / 92 \\
(3.3 \%)\end{array}$ & $7 / 85(8.2 \%)$ & $\begin{array}{c}P=0.023, \\
\mathrm{OR}=0.484, \\
\mathrm{CI}=0.258-0.907\end{array}$ \\
\hline \multicolumn{4}{|l|}{ Other diseases } \\
\hline Diabetics & $67.0 \%$ & & \\
\hline Diabetes for $5-\leq 10$ years & $91.7 \%$ & & \\
\hline Have previous stroke and diabetic & $65.4 \%$ & & \\
\hline Hypertensive & $71.4 \%$ & $0 \%$ & \\
\hline Hypertension for $5-\leq 10$ years & $88.9 \%$ & & \\
\hline Have previous stroke and hypertensive & $69.2 \%$ & & \\
\hline Heart, carotid disease and atrial fibrillation & $52.1 \%$ & $0 \%$ & \\
\hline Previous stroke and heart diseases & $46.2 \%$ & & \\
\hline
\end{tabular}

We conducted the analysis for the two polymorphisms considering mutant genotype versus the wild genotype of the NOS3 $894 \mathrm{G}>\mathrm{T}$ and 786T $>$ C polymorphisms (GT + TT vs. GG) and (TC + CC vs. TT respectively). The genotype analysis provides evidence that the frequency of mutant 894GT + TT genotypes of NOS3 $894 \mathrm{G}>\mathrm{T}$ was significantly higher in stroke patients than in the controls $\left(\chi^{2}=4.36, P=0.037, \mathrm{OR}=1.936, \mathrm{CI}=1.04\right.$ to 3.6$)$ (Table 1 , Figure 1$)$, Whereas the association of the NOS3 $786 \mathrm{TC}+\mathrm{CC}$ gene polymorphism with the controls $(P$ $=0.023, \mathrm{OR}=0.484, \mathrm{CI}=0.258-0.907)$ indicates a possible protective 


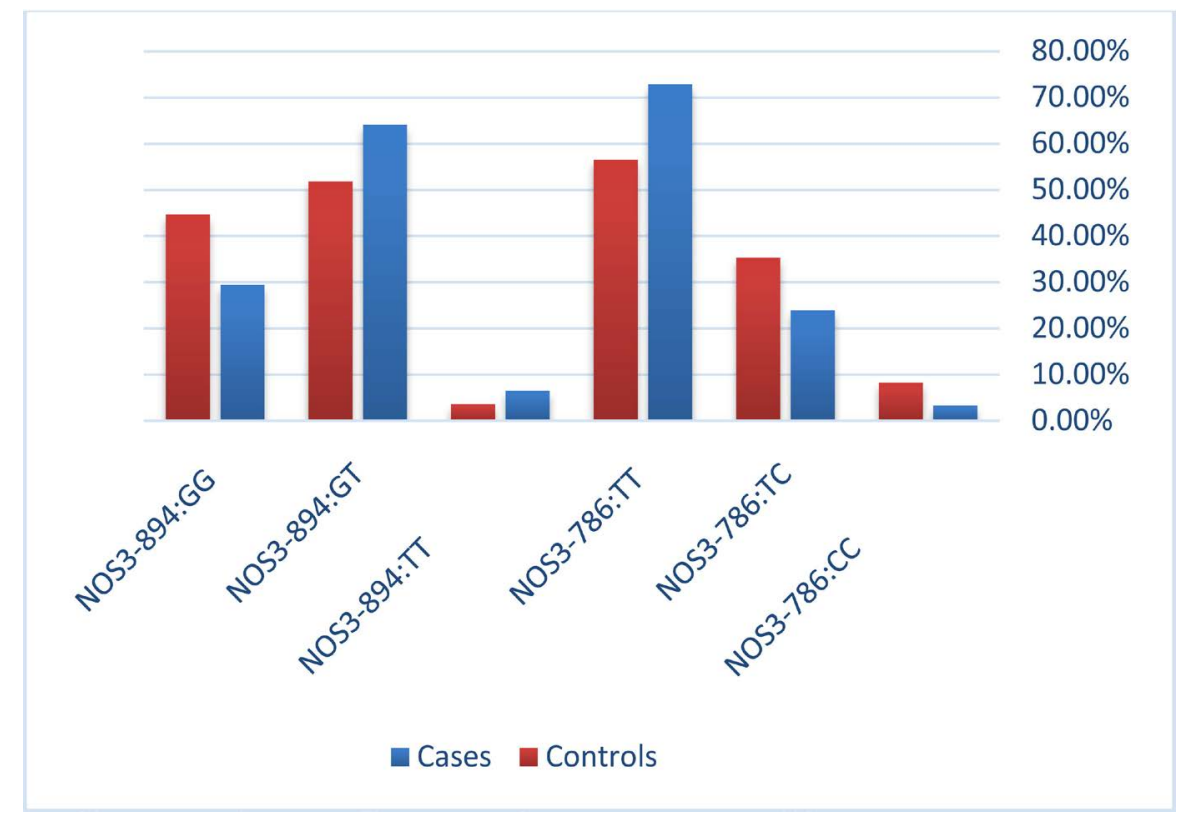

Figure 1. Comparison of the NOS3 gene polymorphisms between stroke patients (cases) and controls.

role of this polymorphism against stroke in this population (Table 1, Figure 1). The level of nitric oxide in stroke patients was significantly low compared to healthy controls $(P<0.005)$.

$67 \%$ of stroke are diabetics, of which $91.7 \%$ are diabetic for $5-\leq 10$ years. Hypertension was reported in $71.4 \%$ of the cases, of which $88.9 \%$ are hypertensive for $5-\leq 10$ years. More than half of stroke patients (52.1\%) have different types of heart diseases (Table 1). High frequency of diabetes, hypertension and heart diseases $(65.4 \%, 69.2 \%$ and $46.2 \%$ respectively) are reported in patients who have previous stroke. More over $50 \%$ of the cases with previous stroke are diabetic and hypertensive.

Figure 1 Shows higher frequency of the mutant genotype GT \& TT of the NOS3 $894 \mathrm{G}>\mathrm{T}$ polymorphism in cases compared to controls $(P=0.037)$. Whereas the mutant genotype TC \& CC of NOS3 786T > C polymorphism showed higher frequency in controls compared to cases $(P=0.023)$.

\section{Discussion}

Stroke was known to be a third leading cause of death globally but since the early $20^{\text {th }}$ century, the stroke mortality has witnessed a decline in the developed countries [1], on the contrary, the incidence of stroke in Bahrain is doubled during the last sixteen years [5] [6]. This could be explained by extreme changes in the lifestyle [5] that lead to the increase of risk-factor prevalence such as sedentary life, smoking, hypertension, diabetes, atherosclerosis in this population [5].

Although stroke is a multifactorial disease; a strong evidence of the genetic contribution to disease predisposition was reported in previous studies [7] [8] [9] [23] [24]. To the best of our knowledge this is the first genetic study of stroke 
in Bahrain targeting the NOS3 polymorphisms. In this study we include Bahraini population only; excluding any non Bahraini residence in an attempt to avoid the effect of the population stratification.

The three types of stroke were observed (Ischemic, hemorrhagic and transient ischemic attack), however the ischemic stroke (IS) was $91.4 \%$ which is higher than the global percentage (IS $=80 \%$ globally).

NOS3 was demonstrated as a biologically plausible candidate for study as a susceptibility gene for stroke in several ethnic groups, as it is a constitutive producer of a vasoactive molecule the nitric oxide [12] [16] [17] [18] and also confers stroke protection by upregulation of eNOS [16], however, the results remained controversial [17] [18] [19] [20] [25] [26] [27] [28].

Our result revealed a significant association of the mutant $894 \mathrm{GT}+\mathrm{TT}$ genotypes of the NOS3 $894 \mathrm{G}>\mathrm{T}$ polymorphism with stroke predisposition $\left(\chi^{2}=\right.$ 4.36, $P=0.037$ ) which is consistent with the finding of the previous studies [27] and those conducted in Korean and other Asian population [19] [20]. This indicates that NOS3 $894 \mathrm{G}>\mathrm{T}$ polymorphism is a predisposing risk factor of stroke in Bahraini population and having the mutant genotype (GT and TT) confer two folds excess risk of stroke ( $\mathrm{OR}=1.936)$.

In contrast an association of the NOS3 786 $>$ T $>$ polymorphism and the stroke predisposition $(P=0.023)$ suggesting that the mutant $\mathrm{C}$ allele might have a protective effect against stroke in this population, however the strength of this association was rather low $(\mathrm{OR}=0.484)$.

About half (46/93 (49.5\%)) of stroke cases are at age $\leq 40-65$. Previous stroke is a significant non-modifiable risk factor of the disease $(P=0.001, \mathrm{OR}=1.4)$. $50 \%$ of the cases with previous stroke are diabetic and hypertensive.

Also the disease risk factors of stroke (diabetes, hypertension or heart diseases) were reported with high frequency among stroke patients $(67 \%, 71.4 \%$ and $52.1 \%$ respectively). $91.7 \%, 88.9 \%$ are diabetic or hypertensive for $5-\leq 10$ years respectively. All these indicate that the stroke and the disease risk factors attack people at the reproductive age and reflects the consequences of adoption of new lifestyle [1] [2] [3] [4] [29], that expected to increase peoples' predisposition to these diseases at early age, which is an alarming situation that cause socio-economic burden to both the family and health services. Given the crucial role of the NOS3 in the relaxation of vascular smooth muscle [12] [18], the NOS3 polymorphisms might play role in the susceptibility to diabetes, hypertension or heart diseases and this need to be elucidated

This finding reflect that "beside the genetic contribution", the role of the lifestyle in the predisposition to stroke or to diseases causing stroke should not be ignored.

\section{Conclusions}

Our results clearly showed an association of the functional exonic variant NOS3 G894T polymorphism with the stroke predisposition in Bahrainis. High fre- 
quency of diabetes, hypertension or heart diseases among stroke patients reflects the important role of these diseases in stroke predisposition and their occurrence at a reproductive age must raise the attention of health services to implement strategy that allow both an early identification of individuals susceptible to the disease and to improve diseases' risk factor management.

In an attempt to reduce a possible occurrence of population sub structure which is one of the drawbacks of the case-control study design, we recruit in this study only the Bahraini Nationals.

Given the fact that there is a strong consanguinity within the Bahraini population, further study including large samples is recommended and it is expected to provide more evidence for the association of these polymorphisms with stroke predisposition in this population.

\section{Acknowledgements}

We would like to thank Dr. Diab A. for his invaluable assistance and maintenance of the gel documentation system. The fund from Princess Al-Jawhara Center, Arabian Gulf University, Bahrain and Al Neelain University-Sudan are greatly appreciated.

\section{Competing Interests}

The authors declare that they have no competing interests.

\section{References}

[1] Lackland, D.T., Roccella, E.J., Deutsch, A.F., et al. (2014) Factors Influencing the Decline in Stroke Mortality: A Statement from the American Heart Association/American Stroke Association. Stroke, 45, 315-353. https://doi.org/10.1161/01.str.0000437068.30550.cf

[2] Sacco, R.L., Wolf, P.A. and Gorelick, P.B. (1999) Risk Factors and Their Management for Stroke Prevention, Outlook for 1999 and Beyond. Neurology, 53, S15-S24. https://doi.org/10.1212/WNL.53.7.15A

[3] Benamer, H.T. and Grosset, D. (2009) Stroke in Arab Countries: A Systematic Literature Review. Journal of the Neurological Sciences, 284, 8-23. https://doi.org/10.1016/j.jns.2009.04.029

[4] Go, A.S., Mozaffarian, D., Roger, V.L., et al. (2013) Heart Disease and Stroke Statistics-2013 Update: A Report from the American Heart Association. Circulation, 127, e6-e245. https://doi.org/10.1161/CIR.0b013e31828124ad

[5] Al Banna, M., Baldawi, H., Kadhim, A., Humaidan, H. and Whitford, D.L. (2015) Stroke in Bahrain: Rising Incidence, Multiple Risk Factors, and Suboptimal Care. International Journal of Stroke, 10, 615-618. https://doi.org/10.1111/ijs.12513

[6] Al-Jishi, A.A. and Mohan, P.K. (2000) Profile of Stroke in Bahrain. Neurosciences (Riyadh), 5, 30-34.

[7] Flossmann, E., Schulz, U.G. and Rothwell, P.M. (2004) Systematic Review of Methods and Results of Studies of the Genetic Epidemiology of Ischemic Stroke. Stroke, 35, 212-227. https://doi.org/10.1161/01.STR.0000107187.84390.AA

[8] Razvi, S.S. and Bone, I. (2006) Single Gene Disorders Causing Ischaemic Stroke. 
Journal of Neurology, 253, 685-700. https://doi.org/10.1007/s00415-006-0048-8

[9] John, F., Senthil, R. and Pradeep, K. (2007) The Role of Genetics in Stroke. International Journal of Stroke, 83, 590-595. https://doi.org/10.1136/pgmj.2007.060319

[10] James, F.M., Bradford, B.W. and Stephen, S.R. (2011) Genetic Susceptibility to Ischemic Stroke. Nature Reviews Neurology, 7, 369-378. https://doi.org/10.1038/nrneurol.2011.80

[11] Pezzini, A. (2012) Genetic Determinants of Juvenile Stroke. Thrombosis Research, 129, 330-335.

[12] Ignarro, L.J., Buga, G.M., Wood, K.S., Byrns, R.E. and Chaudhuri, G. (1987) Endothelium-Derived Relaxing Factor Produced and Released from Artery and Vein Is Nitric Oxide. Proceedings of the National Academy of Sciences of the United States of America, 84, 9265-9269

[13] Riddell, D.R. and Owen, J.S. (1999) Nitric Oxide and Platelet Aggregation. Vitamins and Hormones, 57, 25-48.

[14] van Goor, H., Albrecht, E.W., Heeringa, P., et al. (2001) Nitric Oxide Inhibition Enhances Platelet Aggregation in Experimental Anti-Thy-1 Nephritis. Nitric Oxide, 5, 525-533. https://doi.org/10.1006/niox.2001.0382

[15] Kurose, I., Kubes, P., Wolf, R., et al. (1993) Inhibition of Nitric Oxide Production. Mechanisms of Vascular Albumin Leakage. Circulation Research, 73, 164-171. https://doi.org/10.1161/01.RES.73.1.164

[16] Endres, M., Laufs, U., Liao, J.K. and Moskowitz, M.A. (2004) Targeting eNOS for Stroke Protection. Trends Neurosciences, 27, 283-289. https://doi.org/10.1016/j.tins.2004.03.009

[17] Munafo, M.R. and Flint, J. (2004) Meta-Analysis of Genetic Association Studies. Trends Genetics, 20, 439-444. https://doi.org/10.1016/j.tig.2004.06.014

[18] Dutra, A.V., Lin, H.-F., Juo, S.-H., et al. (2006) Analysis of the Endothelial Nitric Oxide Synthase Gene as a Modifier of the Cerebral Response to Ischemia. Journal of Stroke, 15, 128-131.

[19] Wang, M.Y., Jiang, X.B., Wu, W.L. and Zhang, D.F. (2013) Endothelial NO Synthase Gene Polymorphisms and Risk of Ischemic Stroke in Asian Population: A Meta-Analysis. PLoS ONE, 8, e60472.

[20] Kang, M.K., Kim, O.J., Jeon, Y.J., Kim, H.S., et al. (2014) Interplay between Polymorphisms in the Endothelial Nitric Oxide Synthase (eNOS) Gene and Metabolic Syndrome in Determining the Risk of Ischemic Stroke in Koreans. Journal of Neurological Sciences, 344, 55-59. https://doi.org/10.1016/j.jns.2014.06.020

[21] Census Summary Result (2010) Population, Housing, Buildings, Establishments and Agriculture Census.

http://www.cio.gov.bh/CIO_ARA/English/Publications/Census/2011\%2009\%2018\% 20Final\%20English\%20Census\%202010\%20Summary\%20\%20Results\%20-\%20Revi ew\%201.pdf

[22] Al Arrayed, S.S. Genetic Diseases in Bahrain. Genetic Disorders in the Arab World. http://www.academia.edu/763838/Genetic_Diseases_in_Bahrain

[23] Meschia, J.F., Worrall, B.B. and Rich, S.S. (2011) Genetic Susceptibility to Ischemic Stroke. Nature Reviews, Neurology, 7, 369-378. https://doi.org/10.1038/nrneurol.2011.80

[24] Loo, K.W., Heidi, S., Anthony, A., Emily, C., Larisa, M.H., Siew, H.G. and Lyn, R.G. (2015) A Potential Epigenetic Marker Mediating Serum Folate and Vitamin $B_{12}$ Levels Contributes to the Risk of Ischemic Stroke. BioMed Research International, 
2015, Article ID 167976. http://doi.org/10.1155/2015/167976

[25] Radomski, M.W., Palmer, R.M. and Moncada, S. (1987) Endogenous Nitric Oxide Inhibits Human Platelet Adhesion to Vascular Endothelium. The Lancet, 330, 1057-1058. https://doi.org/10.1016/S0140-6736(87)91481-4

[26] Della-Morte, D., Guadagni, F., Palmirotta, R., et al. (2012) Genetics of Ischemic Stroke, Stroke-Related Risk Factors, Stroke Precursors and Treatments. Pharmacogenomics, 13, 595-613. https://doi.org/10.2217/pgs.12.14

[27] Morris, C.M., Ballard, C.G., Allan, L., Rowan, E., Stephens, S., Firbank, M., Ford, G.A., Kenny, R.A., O’Brien, J.T. and Kalaria, R.N. (2011) NOS3 Gene rs1799983 Polymorphism and Incident Dementia in Elderly Stroke Survivors. Neurobiology of Aging, 32, 554.e1-554.e6. https://doi.org/10.1016/j.neurobiolaging.2010.06.012

[28] Green, D.J. (2009) Exercise Training as Vascular Medicine: Direct Impacts on the Vasculature in Humans. Exercise and Sport Sciences Reviews, 37, 196-202.

[29] Abdul Rahman, O.M. (1998) Change in Dietary Habits, Lifestyle and Trend in Diseases in the GCC Countries. Bahrain Medical Bulletin, 20, 87-90. 